\title{
Crítica e resignação. $O$ trânsito constante entre categorias nativas e categorias analíticas: a força política e estética da categoria indústria cultural.
}

Elder Maia Alves*

Resumo: Este trabalho abriga o propósito de descortinar os diferentes usos analíticos e políticos da categoria de indústria cultural. Para tanto, busca apresentar a consecução e regularidade de um trânsito simbólico e discursivo envolvendo duas ordens de categorias conceituais: as categorias nativas (forjadas, elaboradas e reelaboradas pelos agentes sociais diante das contingências que compõem as pautas e os recursos lingüísticos em meio ao cotidiano prosaico da experiência psicossocial) e as categorias analíticas (talhadas como recursos teórico-metodológicos para compreender e interpretar a estruturação da vida cotidiana dos agentes, seus impasses, tensões e construções de horizontes de significado dentro da dinâmica sóciohistórica). A proximidade dessas duas ordens conceituais, assim como seu trânsito permanente, imprimiu uma importância política e analítica particular ao conceito de indústria cultural no decurso da segunda metade do século XX.

Palavras-chave: indústria cultural, categorias analíticas, categorias nativas e modernização cultural.

Critical and resignation. The constant transit between native categories and analytic categories: the political force and esthetics of the category cultural industry.

\begin{abstract}
This article intends to expound the different uses, analytical and political, of culture industry category. For that purpose, it attempts to present the achievement and regularity of a symbolic and discursive transit which involves two orders of conceptual categories: the native categories (forged, developed and reworked by the social agents towards the contingencies that compose the guidelines and the linguistic resources in the midst of the prosaic quotidian of the psychosocial experience) and the analytical categories (shaped as theoretical and methodological resources for understanding and interpretating the structure of everyday life of agents, their dilemmas, tensions and constructions of horizons of meaning within the socio-historical dynamic). The proximity of these two conceptual orders, as well as its permanent transit, imprinted a particular value, political and analytical, to the concept of culture industry during the second half of the twentieth century.
\end{abstract}

* Doutor em sociologia, professor Adjunto I do Instituto de Ciências Sociais da Universidade Federal de Alagoas. E-Mail: epmaia@hotmail.com 
Key-words: cultural industry, an analytical category, native category and cultural modernization.

\section{Introdução}

O processo de constituição do conceito de indústria cultural é resultado das contingências do século XX. Sua feitura e expansão seguiu de perto o próprio recrudescimento do processo de industrialização do simbólico no decurso do século XX. Se este trabalho abrigasse o objetivo de rastrear os componentes analíticos que integram essa categoria veríamos que há uma combinatória de matrizes distintas da teoria social, assim como ambigüidades e novas incorporações. No entanto, esse trabalho não se interessa propriamente pela realização de uma história do conceito à maneira de uma localização arqueológica de seus princípios e filiações. Este trabalho pretende desvelar, na medida do possível, os efeitos práticos do processo de consolidação, expansão e apropriação do conceito de indústria cultural.

Esse processo ocorreu em meio à própria estruturação da modernização cultural, sobretudo na América Latina. Esse processo foi realizado por diferentes gerações de intelectuais-artistas, movimentos de contracultura, grupos de pressão, vanguardas artísticas, entre outras. A rigor, o trabalho em tela preocupa-se menos em discutir e problematizar os significados internos do conceito e mais sua incorporação na pauta das práticas discursivas dos grupos político-culturais no decurso da segunda metade do século XX.

Nesse sentido, sustenta a hipótese de que o conceito de indústria cultural é uma categoria cindida em duas dimensões antípodas, que por vezes se aproximaram, mas que, na teoria sociológica, assumem funções e desdobramentos bastante eqüidistantes. $\mathrm{O}$ conceito nasce, como se verá, simultaneamente como uma categoria sociológica, como uma peça teórica talhada para compreender e explicar a trama de relação entre arte, técnica e estética, e também como um manifesto critica-político, com forte caráter normativo. Esses dois aspectos, por vezes, caminharam paralelos, cada um, a sua maneira, fortaleceu e deu ossatura a categoria de indústria cultural, tanto em termos analíticos, quanto no que tange a consecução de uma crença e uma convicção ético-moral.

Com efeito, é possível pensar no conceito de indústria cultural como uma categoria que abriga um caráter analítico, mas paralelamente como uma categoria nativa, nos termos de que, por um lado, seu significado se expandiu em função da densidade normativa ali contida, que informou e sedimentou a compreensão e percepção de mitos grupos político-culturais na segunda metade do século XX; por outro, essa expansão só se realizou em meio aos intensos processos de modernização cultural, no interior dos quais a categoria de indústria cultural aparece como um dispositivo explicativo da dinâmica da modernização cultural e, principalmente, como um insumo de critica política e filosófica aos próprios efeitos da modernização cultural. Numa palavra, o conceito de indústria cultural é uma 
categoria de análise quando intenciona explicar os desdobramentos do processo de industrialização do simbólico inscrito na dinâmica do capitalismo tardio, ao passo que também é uma categoria nativa (ressignificada, ressemantizada, apropriada e incorporada como insumo discursivo nas lutas político-culturais) quando informa e sedimenta uma conviç̧ão ético-moral critica dirigida à própria modernização cultural.

Para compreender a especificidade dessas duas dimensões, seus distanciamentos e imbricações, o que se segue busca situar a categoria dentro dos desdobramentos do pensamento hegelo-marxista, chamando atenção especificamente para a consolidação da dimensão nativa do conceito, e, por outro lado, revelando os efeitos práticos da consolidação da dimensão nativa do conceito em meio a experiência da modernização cultural brasileira.

\title{
Indústria cultural: de categoria analítica à categoria nativa
}

\begin{abstract}
"Entre as duas Guerras Mundiais, o filósofo Theodor Adorno se queixava da industrialização das atividades culturais de que ele começava a se dar conta. Essa consciência infeliz em face do progresso industrial do livro, do filme e da música, representa um modelo de um modo de pensar que precisou de mais de cinqüenta anos para se transformara pela aceitação de analisar o real em lugar de fantasiá-lo conforme nossos desejos. (...) $\mathrm{Na}$ realidade é a coisa mais normal do mundo que o processo de industrialização, um dos processos metodológicos e operacionais mais importantes da história humana, também ocorra nos fenômenos culturais. Somente uma concepção elitista faria pensar que a cultura e suas produções poderiam permanecer a parte desse movimento." (TOLILA, 2007, p. 203)
\end{abstract}

O trecho acima foi extraído do livro Economia e cultura, publicado em 2007 pelo sociólogo e economista Paul Tolila, ex-diretor do Departamento de Estudos de Perspectivas e Estatísticas do Ministério da Cultura da França (DEPS). Sua contundência e precisão são reveladoras, traz o núcleo da reflexão desenvolvida neste trabalho. Podemos separar do trecho citado alguns pontos nevrálgicos para a condução dessa reflexão.

Parece, a primeira vista, muito paradoxal que tenha ocorrido uma demora demasiada em perceber o processo de industrialização do simbólico como um processo simultâneo e complementar ao processo de industrialização material, ou em outros termos, que o processo de industrialização tenha se estruturado em duas frentes interdependentes: uma material e outra imaterial. O paradoxo mencionado vem do fato de ter sido exatamente esse um dos grandes méritos dos filósofos sociais da Escola de Frankfurt, ou seja, a perspicácia critica e analítica de apreender um fenômeno que começava a ganhar corpo, revelando as redes de conexão entre

Latitude, Vol. 2, nº 1 , pp.82-105, 2008. 
as transformações técnicas, os regimes de acumulação do capital e os mecanismos de indução para o consumo cultural.

Esse arranjo foi capturado pelos filósofos de Frankfurt a partir de um conjunto de categorias analíticas que formaram uma família conceitual, cujo pai e a mãe são representados pela categoria de indústria cultural. $\mathrm{O}$ desenvolvimento desse conceito dependeu fundamentalmente da experiência de expansão dos mercados de símbolos nos grandes centros metropolitanos norte-americanos, no qual autores como Theodor Adorno se situavam como interpretes privilegiados. A interação e o aprimoramento dos dispositivos técnicos, a recuperação da economia americana após a crise de 1929, aliado ao intenso padrão de urbanização e industrialização, engendraram nos Estados Unidos um verdadeiro modo de produção complementar, ou se quisermos, uma aceleração do padrão de industrialização, que passou a ser também uma industrialização das matrizes orais e visuais, isto é, o estoque de símbolos que compunham a sociedade norteamericana. A conjugação desses fatores resultou no aparecimento de uma esfera cultural laica (WEBER, 1982) baseada em uma imensa estrutura urbana de serviços de entretenimento e diversão.

Se a formação do conceito de indústria cultural levou ao desvelamento de um processo de difícil compreensão empírica, por que então o ex-diretor do DEPS reclama que foram necessários longos cinqüenta anos para que as transformações operadas pelo processo de industrialização do simbólico recebesse a devida atenção? Talvez a resposta esteja exatamente na rapidez com que o conceito de indústria cultural passou de uma categoria analítica (forjada em um contexto específico para dar conta da relação entre técnicas, investimentos, estruturas e interesses) para uma categoria nativa (incorporada e manejada pelos grupos político-culturais como um índice simbólico e afetivo das lutas culturais), como um repertório lingüístico da experiência prática da vida cotidiana, convertendo-se em uma matriz de legitimação de determinadas ações culturais, políticas públicas e movimentos de contracultura.

Não raro, a indistinção entre categorias analíticas - forjadas para apreender a particularidade de certos fenômenos empíricos, e que dependem de certo grau de refletividade (WEBER, 1982; ELIAS, 2001; BOURDIEU, 2006) - e categorias nativas engendradas a partir dos sistemas de práticas nas quais os agentes sociais estão diretamente envolvidos - suscita uma miríade de obstáculos metodológicos. A rigor, a própria diferenciação entre uma e outra é parte de um procedimento metodológico levado a cabo por alguns autores. O constante trânsito e, por vezes, a total imbricação entre ambas, é parte constitutiva do próprio processo social.

No entanto, o esforço metodológico de forjar categorias de analise para compreender a tessitura real das formas de classificação, de auto-representação e de imputação de sentido forjadas pelas categorias nativas é imprescindível, podendo levar, com efeito, a compreensão das razões que levaram, por exemplo, o conceito de indústria cultural a alargar sua matriz de significado, passando de um conceito circunscrito a um nicho acadêmico particular para o universo mais geral das lutas 
político-culturais, ou seja, deslocado para formas de usos que envolvem uma rede de interdependências sociais mais dilatada (ELIAS, 2004).

Há, pois, um fluxo interrupto entre categorias nativas e analiticas. $\mathrm{O}$ trabalho intelectual propriamente dito consiste em retirar da linguagem cotidiana os recursos que possibilitem a feitura de novos artefatos conceituais. Consiste, por assim dizer, em um movimento que busca promover uma dupla hermenêutica (GIDDENS, 2002) ou realizar uma dupla tradução (GERTZ, 2000). Para tanto, é preciso realizar uma critica da própria linguagem, desnaturalizando algumas modalidades de significação e compreensão. O plano analítico de formação dos conceitos se debruça sobre as experiências do mundo da vida (SCHUTZ, 1978) para apreender o sentido e a direção dessas experiências (ELIAS, 2004). O conceito de habitus, por exemplo, é um recurso forjado para apreender os diversos níveis relacionais existentes entre estrutura e agência. Consiste propriamente em apreender os modos pelos quais as estruturas mentais, simbólicas, econômicas e políticas são internalizadas e, simultaneamente, externalizadas. É uma tentativa criativa de desconstrução de dicotomias estanques.

O plano da experiência que forma as sensações e emoções do mundo da vida cotidiana, ou seja, aquele que envolve a formação do habitus (BOURDIEU, 2005) também envolve os pesquisadores. Ocorre, no entanto, que o espaço social de penetração das categorias analíticas é muito mais restrito, está circunscrito a círculos hermenêuticos (GIDDENS, 2002) que se caracterizam pelo rigor do trabalho acadêmico. Nesse sentido, conceitos como habitus, figuração, campo, poder simbólico, economia pulsional, balança de poder, auto-imagem, monopólio de sentido, entre muitos outros, não informam muito a compreensão coletiva e não fazem parte da matériaprima cotidiana de orientação dos complexos de condutas, assim como não fazem parte das disputas, das tensões, das reciprocidades que costuram as teias de relações mais amplas.

Os conceitos sociológicos, isto é, as categorias analiticas cumprem a função de apreender o conjunto das experiências sociais, que nas suas constituições e vicissitudes formam toda sorte de categorias nativas. Eles não gozam de nenhuma primazia ontológica sobre o plano da experiência propriamente dita, apenas fazem parte de um postulado epistemológico específico e do desenho metodológico esculpido por alguns autores. No entanto, há conceitos que se convertem em verdadeiras usinas de produção de significados coletivos, que ultrapassam as fronteiras de círculos acadêmicos mais circunscritos. Esses conceitos passam a operar como uma matriz de significado comprometida com éticas de vida e cosmologias gerais. Foi exatamente o que ocorreu com os conceitos de classe, ideologia e indústria cultural.

Poder-se-ia perguntar por que esses conceitos lograram tanta legitimidade e passaram a informar as compreensões coletivas, atuando como espécie de abastecedores das demandas de significado, isto é, da passagem do conceito de indústria cultural enquanto uma categoria mais de cunho analítico para uma categoria marcadamente nativa? Essa indagação foge aos objetivos desse trabalho, seria preciso realizar uma minuciosa história conceitual, tendo como uma de suas 
faces mais importante uma pergunta sobre as condições sociais de emergência e legitimação desses conceitos. Gostaria de reter apenas, de maneira sumária, o movimento que levou a feitura do conceito de indústria cultural e a sua conversão em um poderoso insumo lingüístico-discursivo das lutas político-culturais, ou seja, aos seus usos específicos.

O conceito de indústria cultural foi desenvolvido nos anos quarenta do século passado, aparece pela primeira vez nos trabalhos de Theodor Adorno e Max Horkheimer em um ensaio intitulado Indústria cultural: o iluminismo como mistificação das massas, datado de 1942, mas só publicado em 1947. O conceito nasce sob o auspício de um duplo registro: por um lado é instrumento teórico-analítico, capaz de contribuir para a compreensão do processo de industrialização do simbólico, das especificidades do capitalismo avançado de matriz norte-americana; por outro, revela uma componente critica ao projeto iluminista de modernização. Ambos os registros se desenvolveram de maneira paralela, mas a expansão de um aspecto, o caráter crítico-político, comprometeu (ou pelo menos atenuou) o registro propriamente interpretativo do conceito.

Em seus primeiros trabalhos, Elias recupera a formulação da noção de kultur enquanto uma categoria nativa construída por intelectuais, artistas e ilustrados alemães no decurso do século XVIII. Assim, o autor busca submetê-la aos desígnios e contingências de formação da auto-imagem dos estratos médios e liberais alemães que lutavam para assumir os quadros de direção do Estado. O objetivo do autor é recuperar as linhas gerais de formação dos símbolos lingüísticos de autorepresentação entre os grupos de poder na Alemanha, cotejando os diferentes processos a fim de entender as diferenças de significação entre as formulações de kultur e zivilisation. Nesse cotejamento, o ator mostra as muitas modalidades de lutas simbólicas entre os grupos alemães.

Dentro dos círculos intelectuais dos estratos médios liberais, o termo kultur designava um conjunto de práticas estéticas, artísticas, musicais, filosóficas, religiosas, teológicas e literárias. A designação concentra-se nas práticas de cultivo do espírito e estão diretamente ligadas às atividades simbólicas existentes em uma restrita esfera cultural de fruição e deleite artístico-intelectual. A formulação do conceito decorre, assim, da experiência pessoal que envolve outro conceito, o bildung. Segundo Jessé Souza, o sentido da experiência do bildung repousa na contemplação mística inscrita nas matrizes de formação da teologia alemã. Essas matrizes místico-teológicas potencializam-se nos movimentos literários, filosóficos e estéticos desencadeados na Alemanha a partir do século XVIII, como o romantismo e o idealismo. A partir do século XIX o bildung foi cada vez mais evocado como principio de uma prodigiosa pedagogia humana universal, cujos artífices podem ser encontrados no panteão dos grandes pensadores alemães dos últimos séculos, como Lutero, Kant, Herder, Schiller, Goethe e Hegel. Para Souza, a força desse traço teológico demonstra a reverência quase mística do alemão à cultura (SOUZA, 2000).

Certamente Walter Benjamin retirou subsídios dessa experiência, ele mesmo um intelectual pertencente aos estratos médios liberais urbanos, para compor a 
diferenciação entre valor de aura e valor de exposição e formular uma teoria da produção cultural contemporânea. A mesma fileira na qual se encontram Elias e Souza é engrossada por Zigmunt Bauman. Para este o termo cultura entrou no vocabulário ocidental pautado por um projeto de melhoramentos e ajuste de homens e mulheres, que, a partir do advento da modernidade, sobretudo das transformações do século XVIII, se viram mais ou menos livres dos desígnios divinos.

\begin{abstract}
"O termo 'cultura' foi concebido no interior de uma familia de conceitos que incluía expressões como 'cultivo', 'lavoura', 'criação'- todos significando aperfeiçoamento, seja na prevenção de um prejuízo ou na interrupção e reversão da deterioração. O que o agricultor fazia com a semente por meio da atenção cuidadosa, desde a semeadura até a colheita, podia e devia ser feito com os incipientes seres humanos pela educação e treinamento. As pessoas não nasciam, eram feitas. Precisavam se tornar seres humanos, e nesse processo teriam que ser guiados por outros seres humanos, treinados na arte de educar e treinar seres humanos. " (BAUMAN, 2005, p.61).
\end{abstract}

Essa pedagogia universal, ou seja, essa "agricultura de espíritos", impactou na estruturação nos sistemas de gosto e para a criação dos centros especializados de ensino e produção simbólica a partir do século XIX. Na raiz dessa concepção estão as formulações de kultur e bildung. Quando o romantismo cerra os punhos em um brado de critica e resignação contra as idéias de racionalidade, razão, ordem, planejamento, técnica e eficiência potencializadas pelo Iluminismo, encontrou boa parte de sua munição critica nos grupos de artistas (pintores, escritores, poetas, etc.) e intelectuais (filósofos, jornalistas, professores, críticos) que formavam os chamados circuitos da cultura erudita (museus, academias, salões, cafés, universidades, teatros, entre outros), especializada na produção de bens simbólicos para especialistas, ou seja, para outros produtores.

Existia no século XVIII e XIX, especialmente em países como França, Inglaterra e Alemanha, um circuito de consumo restrito e bastante fechado, que se desdobrava sobre si mesmo, criando modalidades de diferenciação e lutas culturais à medida que o processo de industrialização do simbólico tomava corpo. Quando esse então passa a se instaurar como uma realidade sócio-econômica, tem-se a expansão dos mercados culturais e a respectiva ampliação do consumo simbólico. Esse é o fator desestabilizador - que se contrapõe a uma moralidade consolidada -, pois os mercados culturais ampliados produzem para não-especialistas, para não produtores, em outros termos, para aqueles que não estão aferrados ao desejo cotidiano de auto-cultivo ou de se deixar cultivar por um treinamento exaustivo, seja ele escolar ou familiar, mas também um fator reorganizador das esferas de produção cultural moderna.

Os atos e ações do romantismo, no qual o dueto bildung/kultor ocupa o centro das energias de contestação, atravessam o século XIX informando muitos 
pesquisadores europeus. Segundo Peter Burke, localiza-se nesse século a invenção contemporânea do conceito de cultura popular, que veio a se somar a outros um pouco mais antigos, como povo e nação, todos convertidos em elementos de pesquisa empírica que deveriam ser buscados nas camadas mais escondidas da alma popular, como reminiscências que só se apresentariam por meio de um trabalho sistemático de procura. Para isso foram fundadas, nas últimas décadas do século, as primeiras associações, organizações e sociedades de folclore (BURKE, 2001).

Renato Ortiz ressalta que a sensibilidade romântica se volta contra as restrições à imaginação, o elemento propulsor passa a ser uma critica aos valores da nascente sociedade burguesa, a seus princípios de cálculo e razão. Eram antes de tudo contra a idéia da venda contida no mercado cultural, ao valor de troca, em suma, a monetarização das relações sociais e, particularmente da cultura. Dirigem suas atenções para noções como espontaneidade e criação, mas não como um atributo de um indivíduo, e sim como algo diluído no todo, na coletividade, como um saber difuso. Voltam-se assim para as noções de povo e popular como um critério de galvanização da nação, como um elo perdido capaz de resolver as contradições entre elite e povo, gerando uma cultura nacional verdadeira e distinta da noção francesa de civilisation, considerada como uma representação falsa e caricata (ELIAS, 1997).

Segundo Ortiz, é nesse momento que parte da intelligensia (MANNHEIM, 2001) alemã se volta para as tradições populares a fim de encontrar um substrato autêntico para a cultura nacional. Elegem-se, para tanto, alguns temas e outros são considerados tabus. Por exemplo, os costumes, as lendas, os folguedos são contemplados, mas, por outro lado, aspectos que envolvem a imigração do camponesa para os centros urbanos, as formas de produção material e imaterial e a experiência do trabalho industrial eram evitados e desdenhados. Tudo que apontasse para aspectos sócio-econômicos, como mercado cultural e/ou produção era, assim, preterido.

É possível sustenta que a partir da segunda metade do século XIX uma regularidade marca a constituição dos campos de produção simbólica: a aproximação, o distanciamento e os atravessamentos que os ligam ao mercado. A comercialização e as trocas monetárias em torno dos bens artístico-culturais criam uma fronteira que separa os partidos "estéticos". Segundo Bourdieu, esses partidos e as posições que os mesmos ocupam nos campos dependem da aproximação ou não do pólo do mercado. Em um pólo vigora a economia não-econômica, baseada na arte pura, na arte pela arte, onde se pratica a aversão pelo ganho da venda direta e os valores do desinteresse, cujos resultados econômicos são sempre a médio e longo prazo, onde a acumulação do capital simbólico é maior, onde se privilegia a produção de competências específicas (ou seja, o cultivo e a arte de cultivar os outros). No outro pólo, estaria a lógica do ganho monetário direto, da acumulação de capital econômico imediato, fazendo do comércio dos bens simbólicos um comércio como tantos outros (BOURDIEU, 2005). 
Pelo destaque de Bourdieu, o mercado é parte constitutiva da estruturação dos campos de produção cultural. Ele atua como um organizador das tomadas de posição, das formações dos discursos, da geração das palavras de ordem, das acumulações de capitais, até quando se pretende acumular capital simbólico é preciso fazê-lo diante da negação do mercado, dos jogos monetários e da venda. Faz parte da produção da crença, do jogo de estruturação dos campos, da tessitura do habitus e da acumulação dos capitais desprezar o mercado. Esse desdém produz categorias estéticas e conceituais, escolas artísticas e formas de filiação. Por exemplo, foi em meio ao crescimento e diferenciação dos mercados e suas respectivas formas de monetarização, industrialização e consumo que se forjou a clássica equação (com pretensão analítica) tripartide entre os níveis de cultura, isto é, cultura erudita ("elevada" e "cultivada"), cultura popular ("pura", "espontânea", "autêntica" e "ingênua") e cultura de massa ("padronizada", "artificial" e "ruim").

Essa equação informou durante muito tempo a compreensão sociológica, levando-a mais para um beco sem saída do que para uma oportunidade de compreensão e interpretação. Essa divisão, eivada de moralidade e do envolvimento direto dos próprios grupos nas lutas de ocupação das posições que se formavam no interior dos campos, corresponde mais a uma categoria nativa do que propriamente uma categoria sociológica analítica. É a essa divisão que se deve parte da demora aludida acima através da fala de Tolila.

A equação conceitual que estabelece os níveis de cultura, como de resto muitas outras que nutrem essa problemática, deve sua existência ao dueto mercado/consumo cultural. Até bem pouco tempo essas eram palavras proibidas nos meios artísticos de realização. Havia uma espessa couraça de moralidade, boa parte dela construída a partir do potencial critico presente na formulação do conceito de indústria cultural, que cerrava os punhos para essas palavras. Ocorre, no entanto, que mercado e consumo encerram sistemas de relações e práticas simbólicas, ao passo que são categorias analíticas que criam possibilidades de compreensão e interpretação. Repousam ambos nas próprias conseqüências da modernidade, que traz no seu bojo os processos de industrialização do simbólico, de industrialização material, de formação do Estado-nação, de urbanização, do trabalho rotineiro e dos sistemas de diversão e lazer.

Basta nos debruçarmos sobre dois exemplos para notar o quanto o mercado cultural vem se constituído como uma regularidade na modernidade. Em 1857 John Ruskin preferiu um conjunto de palestras em Londres e Manchester, mais tarde reunidas em um livro publicadas sob o título de A economia política da arte. As palestras eram verdadeiras aulas sobre a organização interna das modalidades de investimentos, dos riscos e das possibilidades contidas no mercado de arte. Eram conselhos públicos e sugestões de investimento, todos baseados em uma vasta erudição critica voltada para a literatura e, sobretudo, para as artes plásticas. O autor aborda o tema a partir da lente geral da economia política liberal inglesa do século XIX, isto é, em uma configuração em que o Estado pouco aparece como comprador, demandante e consumidor. 
As palestras de Ruskin revelam características fundamentais de todo mercado e aspectos embrionários que levaram às transformações técnicoeconômicas responsáveis pela formação dos circuitos de bens simbólicos ampliados: público, investimentos, estratégia de ganho, produção, demanda, consumo, etc. A existência de um crítico de arte direcionado para os aspectos econômicos da mesma revela a especialização do mercado, que além de seus consumidores (ou seja, os consumidores do luxo) também tinha os críticos puros (os críticos estéticos), os investidores (bancos e companhias) e os especialistas do olhar do tempo, da sucessão das formas e estilos: os historiadores da arte. A estruturação do mercado e dos aspectos monetários intrínsecos a ele, trouxe consigo uma luta entre sistemas de valores e éticas de vida.

Nessa mesma senda, Ortiz fala que existiram dois séculos XIX na França. Um que vai mais ou menos até meados da década de quarenta, e o outro que se desenrola a partir do início da década de cinqüenta. O que levou o autor a identificar dois séculos na França advém do repertório ainda incipiente de mudanças encetadas pelo processo de industrialização, que, por sua vez, trouxe consigo também a industrialização do simbólico. As transformações nos parques gráficos, o barateamento do custo do papel, o crescimento do público, o aumento do fluxo de transmissão de notícias e as melhorias nas formas de deslocamento (ferrovias e bondes), gerou uma expansão no mercado editorial francês.

Em uma década aumentou significativamente a venda de jornais, revistas e livros. A segmentação dos públicos alcançou todas as faixas de renda e níveis etários. Segundo o autor, a entrada do segundo século XIX representou uma racionalização geral do setor editorial, incorporando dispositivos como a assinatura e a entrega doméstica. Os projetos republicanos de expansão dos serviços de escolarização e o recrutamento de mão-de-obra para os centros urbanos fizeram surgir uma grande imprensa, com jornais baratos, dedicados a crimes e a casos policiais, além daqueles especializados em política e literatura. Em 1865 a venda de jornais ultrapassa pela primeira vez a venda de livros.

Essas transformações criaram as condições para uma grande especialização dos sistemas de gosto, que mais tarde se tornou uma componente identificadora do período conhecido como Belle Époque, que vai da década de 1880 até 1914. A grande expansão do mercado editorial exigiu, em contra partida, a conversão dos contingentes de analfabetos em leitores. Segundo o autor, no final do século XIX todo cidadão francês era um leitor impotencial (ORTIZ, 1999). Essa unidade lingüística alcançada foi fundamental para a formação e consolidação da memória nacional, atuando como uma espécie de meio-fim.

O dueto entre mercado cultural e monetarização da arte, estrutural ao próprio processo de industrialização do simbólico, causou nos autores, interpretes e críticos marcados pela experiência do bildung/kultur e, por sua vez, também tributários da ética de vida romântica, uma critica resignada e melancólica. Não foi diferente com os artífices do conceito de indústria cultural. É possível imaginar o quanto os efeitos da relação entre técnica e símbolo, entre imaterialidade e materialidade, entre monetarização e cultura, impactou os filósofos de Frankfurt. 
Como compatibilizar esses processos? Como equacionar arte e técnica, o valor conferido a aura e a reprodução de imagens e sons, como se perceber um autocultivador contumaz de si e dos outros (um "agricultor de espíritos") diante da não-especialização do consumo, diante da racionalidade técnico-econômica de um sistema que torna o invisível em visível, como pensar a prática do kultur/billdung diante da ausência de tempo, tomado todo pelo trabalho incessante?

Ao mesmo tempo em que essas questões aguçaram a imaginação sociológica, desembocando em um trabalho empírico de investigação, que resultou no próprio aparecimento do conceito de indústria cultural, gerou uma vigorosa critica estética e política. O conceito é resultado, assim, de uma combinação entre um rigoroso trabalho teórico com um forte apelo critico, com tintas vibrantes de uma densa couraça ético-moral. Uma espécie de grito de alerta em face das ameaças que a indústria cultural e a cultura de massa traziam para o espírito, e mais, como uma denúncia à promessa não cumprida da modernidade, que se pretendia um projeto racional em direção à libertação das consciências, à individualização e à felicidade (WIGGERSHAUS, 2002).

A critica à reprodutibilidade técnica aparece a nos trabalhos empíricos realizados por Adorno nos Estados Unidos nos anos trinta. Convidado por Paul Lazarsfeld para integrar a equipe de pesquisa de um grande projeto sobre a radiodifusão (O Princeton Radio Research Project), no qual assume a função de diretor da seção musical, intitulada Essential Value of Radio to All Types of Listeners (o valor essencial do rádio para todos os tipos de ouvintes), Adorno realiza uma série de análise sobre música popular, compilando uma teoria geral do ouvinte. Suas interpretações sobre a música concentram-se em dois pontos interdependentes.

Primeiro, a noção de estimulantes externos, segundo a noção de pseudoindividualização. A racionalidade da indústria e os processos de tecnificação total da vida engendraram a formatação de outro tipo de racionalidade, aquela que produziria, por meio da aliança entre meio e conteúdo estimulantes externos, uma espécie de entorpecente cultural que relaxaria os ânimos e aplacaria as muitas tensões da rotina. $\mathrm{O}$ outro ponto repousa na noção de falsa sensação de individualidade, que, também movida ela racionalidade da aliança entre meio e conteúdo, criaria nos consumidores uma individualização às avessas, pois o resultado dos dois pontos seria a estandardização das consciências, uma padronização estanque e amordaçadora. O esforço da rotina do trabalho levaria os ouvintes a procuraram recompensas externas, fornecidas pela música popular de massa, produzida e/ou transmitida via rádio. A atenção repetitiva ligada às rotinas do trabalho e convertida, segundo Adorno, em desatenção e distração por parte do ouvinte, relegando-o ao simples entretenimento.

"O êxtase é estilizado como as dos selvagens batendo os tambores da guerra (....) Os consumidores querem e pseudoindividualizados, porque seu ócio é uma fuga do mundo do trabalho, e, ao mesmo tempo, é moldado a partir das atitudes psicológicas a que esse mundo os habitua. A música popular é para as massas um perpétuo feriado. (...) a função dessa

Latitude, Vol. 2, $\mathrm{n}^{\circ} 1, \mathrm{pp} .82-105,2008$. 
música, aquela de cunho sentimental, é precisamente o alívio temporário dado à consciência de alguém que perdeu a fonte de inspiração (....) A música emocional torna-se a imagem da mãe que diz: 'venha e chore minha criança'. É a catarse para as massas, mas uma catarse que mantém todos ainda mais firmes (....) Uma música que permite aos seus ouvintes confessar toda sua infelicidade, reconciliando-os a sua dependência social por meio desse 'alívio'. (ADORNO, 2000, p. 215).

Um dos resultados da pesquisa sobre a radiodifusão e a produção musical por ela veiculada aparece no trabalho $A$ sinfonia do radio. Nesse, realizado em meio ao debate suscitado por conta da publicação do artigo de Benjamin, A obra de arte na época de sua reprodutibilidade técnica, Adorno ressalta que a música produzida no rádio fornece apenas uma aparente ilusão de realidade, na verdade opera como a filmagem de uma peça teatral, na qual a exibição da peça não corresponderia ao real da apresentação cênica. A música transmitida no rádio, captada a partir de uma orquestra em estúdio, não corresponderia assim à unicidade da obra, à sua realidade intrínseca. A inautenticidade inscrita no sistema de reprodução técnica não se restringe à música, ela alcança sua maior expressão no cinema e na televisão. As palavras do próprio Adorno podem ser elucidativas a esse respeito.

\begin{abstract}
"Da sinfonia resta apenas uma sinfonia em casa (...) Mas quanto menos os ouvintes conhecem a obra não-mutilada sobretudo aqueles que são iniciados pomposamente na cultura musical pelo rádio -, tanto mais exclusivamente são dependentes do radio e são mais sujeitos, em total impotência e inconsciência, ao efeito da neutralização (...) Os únicos que poderiam lucrar alguma coisa sensata com isso, seriam os profissionais do ramo, para quem uma tal sinfonia, despojada da solenidade agitada da sala de concertos, dá a impressão de um texto visto através de uma lupa. Munidos de uma partitura e de um metrônomo, eles poderiam acompanhar a execução para chegar inexoravelmente ao âmago de sua inautenticidade, mas afinal de contas não era esta a finalidade da operação." (ADORNO Apud WIGGERSHAUS, p. 271).
\end{abstract}

A partir dos trabalhos empíricos acerca do rádio e que mais tarde levaram à feitura do conceito de indústria cultural, Adorno sustenta que a mesma análise da mercadoria realizada por Marx pode ser estendida ao mundo dos bens culturais. $\mathrm{O}$ exemplo inconteste desse aspecto estaria novamente na música. Para Adorno o mundo da música contemporânea também é regido pelo valor de troca da forma mercadoria, com uma distinção básica: as mercadorias culturais, como a música produzida no rádio, assumem um valor de uso ilusório. Na verdade, assim como no mundo das demais mercadorias, o valor da mercadoria cultural é fornecido pela relação direta de troca com as demais mercadorias culturais. A operação dissimulada de converter o valor de troca em valor de uso, conferindo a mercadoria cultural um valor simbólico lastreado nas necessidades últimas do espírito, tem 
como resultado, segundo o autor, a "fetichização" da cultura. O caráter específico do fetiche da música, como de resto das demais mercadorias culturais, reside exatamente nessa confusão, ou melhor, nessa dissimulação programada (ADORNO, 2000).

Para o autor de Frankfurt, o mundo poderia ser sistematizado em um conjunto de variáveis integrantes de um sistema. O controle desse sistema demandaria uma racionalidade técnica e uma previsibilidade que conferiria um controle total dessas variáveis. O controle seria possível mediante a capacidade de eliminar as diferenças, de solapar a capacidade subjetiva e individual, reduzindoas ao denominador comum do consumo, isto é, a busca pelos estimulantes externos, que produziria assim uma unidimensionalidade de consciências (MARCUSE, 1969). Cumpriria, pois, a critica sistemática denunciar. E assim o foi. Os efeitos produzidos pela indústria cultural, ou seja, a formação de uma cultura de massa, passou a representar a antípoda direta do kultur e do bildung. É preciso localizar o núcleo crítico do empreendimento Frankfurtiano, ou seja, aquele mesmo que conferiu a Escola de Frankfurt o status de grande teoria comprometida com a crítica estética e política.

O objetivo da teoria critica fundamentava-se na constatação e apresentação de um diagnostico considerado sombrio: a autodestruição do pensamento. Segundo Adorno e Horkheimer, já no prefacio da Dialética do esclarecimento, a humanidade estaria se afundando em uma nova espécie de barbárie. Os indícios dessa barbárie estariam por todos os lados: a homogeneização das consciências paralisadas em sua criatividade pelo consumo da cultura de massa e para a massa; das tendências totalitárias dos estados modernos e da re-mitologização do esclarecimento. A sociedade que assaltava a atenção dos críticos de Frankfurt estava, assim, sobrecarregada de inclinações totalitárias e um incomensurável apetite uniformizador.

Ante a esse quadro, o objetivo da teoria critica, que aparece como uma de suas justificativas epistemológicas, seria então assegurar a emancipação humana através do embate critico pela defesa da diferença, da autonomia individual, da subjetividade, enfim, pelo direito de ser e permanecer diferente. $\mathrm{O}$ objetivo seria descortinar as novas mitologias herdeiras do Iluminismo e de sua promessa de esclarecimento, pois o mesmo esclarecimento que varreu e aniquilou muitas superstições no decurso de sua consolidação estaria agora se re-mitologizando (ADORNO, 2000).

No ensaio Em busca da política, Bauman argumenta que os diagnósticos da teoria critica estariam errados. O que se vê hoje em dia é exatamente o posto dos vaticínios e diagnósticos feitos: não é mais a ameaça sistêmica, seja da indústria cultural e/ou do Estado totalitário, que irrompe contra o foro da subjetividade individual, aniquilando as vozes e as diferenças, mas antes o contrário, é o mundo da subjetividade - aquele concernente às práticas da política-vida (GIDDENS, 2002) - voltada para o corpo e para a individualização, que impõe suas demandas ao mundo da esfera pública (BAUMAN, 2000). Se na primeira metade do século XX a sociedade ocidental moderna estava prenhe de esquemas de anulação do ego e de 
suas formas de auto-constituição (como a arte), no princípio do século XXI essa mesma sociedade está cada vez menos disposta a recolonizar o espaço das grandes questões públicas, que abrangem grandes sistemas e movem infinitas partes interdependentes (BAUMAN, 2000).

A nova tarefa de uma teoria critica contemporânea, assevera Bauman, está hoje justamente em recolonizar certas práticas sistêmicas. Segundo Bauman, a individualização é a grande lei de ferro da modernidade. Nas últimas décadas ela fora potencializada e experimentada em seu grau mais elevado. Seu recrudescimento contemporâneo redundou na concentração do indivíduo como tema e plataforma das múltiplas maneiras de se emancipar, se diferenciar e construir as subjetividades. O desejo de Adorno foi realizado. No entanto, fora exatamente pela realização desse desejo que uma outra esfera da vida humana foi secundarizada: o espaço público de conversão das questões privadas em questões publicas de objeto da política (BAUMAN, 2000).

O imperativo da critica traçou um desenhou teórico baseado na equação entre razão, intencionalidade, consumo e acumulação. No decurso dos anos cinqüienta e sessenta o aumento das interdependências entre os suportes técnicos, que resultou no aparecimento da televisão, a presença dos capitais norteamericanos nos projetos de reconstrução dos países europeus no pós-guerra, aliado às transformações no modo de produção capitalista, que cada mais diversificava sua base produtiva, fez com que a critica contida no conceito de indústria cultural apostasse na existência de uma razão apriorística, baseada no domínio da tecnologia, cuja intencionalidade operava no sentido de instrumentalizar a cultura, convertendo e cristalizando todas as suas faces em uma mercadoria destinada ao consumo, inserida, pois, em um dos eixos do processo de acumulação e reprodução do capital. As linhas gerais do argumento são retiradas dos trabalhos de Adorno e Horkheimer dos anos trinta e foram operacionalizadas a partir de uma simplificação própria das contingências políticas e dos filtros erguidos pelos movimentos de luta cultural.

Essa argumentação critica deslocou o conceito de indústria cultural para o centro das discussões políticas envolvendo o processo de reconstrução dos países europeus, e caiu nos nichos acadêmicos e intelectuais do pós-guerra, sobretudo na Europa, como uma lanterna, uma luz em meio à "escuridão", uma espécie de guia de interpretação critica para as mudanças operadas dentro do sistema capitalista do pós-guerra. O postulado critico sustentou que a racionalidade da indústria cultural partia de uma intencionalidade localizada nos Estados Unidos, que passavam a re-colonizar o mundo com sua indústria do espírito. Forma-se assim uma ordem discursiva, um regime de verdade (FOCAULT, 1986) cuja força analítica de interpretação do real se perde, passando ele mesmo a gora a estruturar o próprio real, pois passa a informar as ações, a inspirar reações, a alavancar movimentos de contestação político-cultural. O conceito passa a conviver com outros de grande extensão de significado e importância política, como alienação, ideologia e classe.

Latitude, Vol.2, nº1, pp.82-105, 2008. 


\section{Indústria cultural: uma categoria nativa na dinâmica da modernização cultural brasileira}

A tradução de uma argumentação marcadamente critica foi feita no Brasil na América Latina a partir do binômio tecnologia e civilização. Simultaneamente a tradução para o português do livro Dialética do esclarecimento, de Adorno e Horkheimer, em meados dos anos sessenta, formaram-se os primeiros cursos de comunicação social no Brasil. Esses cursos foram criados na esteira de ampliação do mercado de bens de consumo culturais, cujo alcance, a julgar pelo crescimento da televisão, passava a ser nacional, e estabelecem um dos principais filtros de leitura e interpretação do conceito de indústria cultural. O conceito foi acolhido como insumo de critica política em meio à expansão da rede de cursos universitários de artes, letras, serviço social, ciências sociais, história, filosofia, comunicação social, entre outros. Pelos bancos dessas faculdades passaram muitos artistas, críticos, professores e artistas que galvanizaram as principais linhagens daquilo que Marcelo Ridenti chamou de revolucionários românticos.

O conceito de indústria cultural operou como um fermento crítico que impulsionava trabalhos estéticos e políticos no sentido de desvelar o caráter instrumental contido na tecnologia de produção e reprodução audiovisual (sobretudo o cinema e a televisão). Importava acentuar o registro antinômico entre cultura nacional versus colonização tecnológica. A dependência de capital e tecnologia não gerava somente uma dependência econômica, mas também criava as bases para uma dependência cultural que, sorrateiramente, se instaurava por meio dos sutis recursos tecnológicos das indústrias culturais estrangeiras, sobretudo a norte-americana (TINHORÃO, 2001).

A equação envolvendo os três níveis de cultura destacada antes é filtrada segundo o registro de uma nova colonização, ainda mais violenta e danosa. Formase assim na América Latina o primado de uma teoria da dependência cultural, como um traço estrutural que necessitaria ser rompido a todo e qualquer custo. Essa teoria certamente informou o critico e historiador musical Jose Ramos Tinhorão, pois na passagem citada de seu texto fica clara a relação entre dependência tecnológica e colonização. Falando propriamente da expansão da televisão nos anos sessenta e setenta, César Bolaño destaca que as teorias da dependência não ajudam muito na compreensão da relação entre capitalismo e cultura:

"O Brasil e justamente um mau exemplo para esse tipo de analise ideológica porque aqui, como no México, o desenvolvimento da indústria de televisão $e$ sua competitividade internacional e maior do que os da maioria dos paises centrais. No inicio dos anos 80, o declínio da influencia americana na TV brasileira era mais do que evidente. No inicio dos 90, a produção nacional do horário das 18 as 24 horas ultrapassa os $80 \%$ nas Rede Globo e Manchete, ficando significativamente acima dos 50\% nas demais. Se tomarmos o

Latitude, Vol. 2, n 1 , pp.82-105, 2008. 
prime time exclusivamente, essa porcentagem aumenta ainda mais, beirando muitas vezes os cem por cento. O simplismo dessas analises decorre de uma visão extremamente limitada do capitalismo monopolista e da evolução da divisão internacional do trabalho a partir do pós-guerra." (BOLAÑO, 2005, p. 173).

Ortiz ressalta que a relação entre cultura e mercado no Brasil, sobretudo nas décadas de sessenta e setenta, período que, segundo o autor, ter-se-ia instaurado um mercado de bens simbólicos nacionalizado, foi marcada por um profundo silêncio. O silêncio destacado por Ortiz, como se pode perceber, não foi de critica, mas substancialmente de projetos empíricos que levassem essa relação ao plano da pesquisa empírica e do trabalho teórico-conceitual, submetendo conceitos como o de indústria cultural a um rigoroso exame acerca de suas potencialidades interpretativas e compreensivas. Exceção seja feita ao trabalho de Sergio Miceli e, mais ainda, aos trabalhos de Jose Mario Ramos Ortiz, além de uma coletânea organizada por Gabriel Cohn nos anos oitenta. Guardadas as devidas proporções, o silêncio atestado por Ortiz se coaduna à demora verificada por Tolilla.

Por outro lado, não se pode dizer que a demora e o silêncio tenham marcado todo o espectro de pensamento da tradição hegelo-marxista e dos demais autores envolvidos com acessa problemática. Parece-me que a expansão demasiada do poder de critica político-cultural não comprometeu inteiramente o trabalho empírico-analítico no sentido de buscar novas formulações e revisões ao conceito de indústria cultural. Segundo Williams, esse conceito representa uma tentativa de mediação entre duas dimensões aparentemente antitéticas, ou seja, como uma espécie de ponte pela qual se poderia cruzar e acessar os mundos da infra-estrutura (condições matérias de produção e meios concretos de produção, em outros termos, a essência) e da super-estrutura (dimensão propriamente ideológica, formada por falsas abstrações, em outros termos, a aparência).

Raymond Williams menciona a dificuldade de compilar um método que o permitisse transitar com segurança pelo mundo da produção simbólica. Após algumas maturações e depurações, o autor desenvolveu a noção de materialismo cultural. Esse movimento realizado por Williams dá início a um processo já em curso dentro da tradição de pensamento hegelo-marxista, mas que vinha ocorrendo de maneira lenta e hesitante. O percurso que chega à trajetória de Williams parte exatamente da feitura do conceito de indústria cultural, ou seja, do paradoxo mencionado antes. O grande deslocamento realizado por Williams, e de resto perseguido desde os anos cinqüenta por autores com Althusser, foi dirigir o método histórico-dialético para o mundo simbólico, mobilizando perguntas sobre as condições sociais de produção simbólica e sobre os meios de produção também presente na produção cultural, ou seja, foi tratar o mundo cultural-simbólico também como uma produção entre outras.

A construção do conceito de indústria cultural é relativamente tardia, tendo em vista que o alcance da profusão de imagens e sons, não só nos Estados Unidos, já se fazia sentir na percepção de críticos e pesquisadores desde as primeiras

Latitude, Vol.2, nº 1 pp.82-105, 2008. 
décadas do século. A noção desenvolvida nos anos quarenta mostra, mais do que uma mediação, uma tentativa de fusão dos mundos da infra-estrutura e da superestrutura. O conceito representa, na sua dimensão propriamente analítica, uma possibilidade de conferir à superestrutura uma certa "dignidade" empírica, isto é, o estatuto (só muito tempo depois conquistado) de dimensão real da existência e, portanto, produtora de realidades. Essa potencialidade não foi de resto, como se viu, explorada. Como o conceito guarda em si dois postulados críticos extremamente caros para a construção da auto-imagem das linhagens de intelectuais e artistas de matriz romântica - as trocas monetárias envolvendo a cultura e a perda progressiva da individualidade e da subjetividade por meio da homogeneização das consciências -, seus desdobramentos teóricos e metodológicos tiveram que esperar.

Seguindo essa senda, é possível perceber, para além da critica, que o conceito desvelou uma possibilidade de mudança metodológica envolvendo a noção de super-estrutura. Houve um deslocamento do significado do conceito de ideologia e de seus termos correspondentes. A partir dos anos sessenta já é possível perceber nos trabalhos de Williams, Gramsci, Althusser e Barthes que havia níveis de mediação entre super-estrutura e infra-estrutura que reclamavam um tratamento teórico mais rigoroso. Na gênese do processo de fermentação do pensamento critico seu objeto foi eminentemente a ideologia. A ideologia cumpriria o papel de reificar a realidade, conspurcando as contradições e atenuando os mecanismos de dominação e controle. Nesses termos, a ideologia seria o cimento que, além de ocultar as contradições profundas da vida real, ligava os muitos "oprimidos" e os poucos "opressores". No entanto, a partir do mergulho na dinâmica do processo de industrialização do simbólico, o objeto vai aos poucos ganhando novos contornos. Constata-se, mediante a incessante produção, profusão e consumo dos bens culturais e de seus dispositivos técnicos correspondentes, que ideologia e realidade não seriam tão antinômicas assim, que esta não pode ser mais tão facilmente evocada contra àquela.

A ideologia mudou seu percurso e seu processo ideológico dentro da própria tradição de pensamento hegelo-marxista. Seu tratamento conceitual passou a receber um novo direcionamento.Em termos gerais, houve um redirecionamento do objeto. Se a ideologia passou a se confundir cada vez mais com a realidade, segue-se que a crítica e a investigação da ideologia (antigo objeto) passou a confundir-se progressivamente com a critica da própria realidade, isto é, com a nova indústria do espírito: a indústria cultural. O objeto passa a ser a indústria cultural enquanto tal, que não é simplesmente a produtora sistemática de ideologias, é ela própria uma grande ideologia.

A rigor, o deslocamento do objeto de investigação acompanhou as vicissitudes do processo sócio-histórico. Antes era a ideologia como superestrutura de dominação, um mundo ideacional ilusório e abstrato, agora é a própria realidade (sua dimensão infra e super estrutural) representada por sua face mais concreta (a indústria cultural), no interior da qual a ideologia está "sorrateiramente" imiscuída, compondo e estruturando a própria realidade. Adorno afirma que não havia mais ideologia no sentido estrito da falsa consciência, mas tudo caminha sim 
para sua duplicação. Ortiz adverte que é preciso sublinhar a idéia de duplicação. Segundo o mesmo, se a distância entre realidade e ilusão tende progressivamente a desaparecer significa dizer que a vida "real" estaria se tornando em algo indistinguível do cinema e da televisão. Com efeito, abrir-se-ia, como de fato se abriu, a possibilidade de se pensar uma teoria da realidade simbólica.

Esse esforço de deslocamento do olhar em direção a realidade simbólica encontrou solo fértil a partir dos anos setenta, sobretudo por conta da reorganização das economias mundiais em direção aos setores de serviço, entre eles os bens e serviços culturais. Há um conjunto de autores que testemunharam as mudanças sócio-econômicas do capitalismo a partir dos anos setenta que são unânimes em destacar a centralidade da cultura e da produção simbólica na experiência da vida contemporânea A expansão mundial dos mercados culturais, sobretudo aqueles ligados à indústria fonográfica e audiovisual, a transformação dos suportes técnicos, aliado reorganização nas estratégias de investimento, ao aumento do tempo livre e a intensificação dos fluxos de deslocamento por meio das inovações nos sistemas de transporte (a chamada terceira revolução industrial), fizeram da produção simbólica (dos bens e serviços culturais) um setor de extrema importância para a estruturação das novas economias mundiais de serviço e, por conseguinte, para a consolidação das sociedades pós-industriais (BELL, 1973).

Howard Hughes, um dos autores que se destacaram pelo estudo da relação entre cultura, turismo e entretenimento ressalta que nas sociedades pós-industriais fabricar é menos importantes, por conseguinte, a prestação de serviços ganha em valorização e em especialização (HUGHES, 2004). Pesquisas realizadas no inicio dos anos noventa revelaram que nos principais países europeus a quantidade de trabalho disponível correspondia a apenas $60 \%$ do total verificado no inicio do século. No entanto, durante o século o Produto Interno Bruto (PIB) de países como a França, por exemplo, havia crescido dez vezes em relação ao verificado nos primeiros anos do século e a produtividade/hora cerca de vinte vezes, enquanto o total de pessoas empregadas aumentou em uma média relativamente baixa. $\mathrm{O}$ crescimento do PIB e a produtividade estão ligados, entre outros fatores, ao aumento da importância do setor terciário, entre eles os setores de serviços financeiros (bancos, corretoras, etc.) e culturais (bens simbólicos e serviços culturais, como o turismo cultural e o entretenimento em larga escala).

A parte da população economicamente ativa que estava empregada nos muitos segmentos que compreendem o setor de serviços correspondia, em 1983, a $65 \%$ nos Estados Unidos, a $64 \%$ na Suécia, a 58\% no Reino Unido, a 56\% na Franca e 52\% para Alemanha e Japão. O emprego cultural aumentou na Europa, por exemplo, entre 1980 e 1991, cerca de 38\% Estima-se que em 1993 cerca de 3\% da população economicamente ativa da França estava empregada no setor de serviços culturais, que correspondia àquela altura a 2,5\% do PIB. Parte desses números pode ser estendida ao Brasil, que nos anos setenta vê sua base produtiva ser diversificada, observando-se um grande crescimento do setor de serviços. Nos anos setenta o Brasil passa a abrigar o sétimo mercado mundial de televisão e o sexto na produção de discos, alem de ser o quinto mercado publicitário do mundo.

Latitude, Vol.2, nº 1 pp.82-105, 2008. 
O conjunto de autores evocado para dar conta da especificidade de tais processos é bastante diferenciado, possuindo um espectro amplo. Vai desde nomes como Raymond Williams, passando pelos representantes dos chamados Estudos Culturais, ate Michael Denning. Esses autores, e muitos outros que passaram a estudar a produção cultural a partir dos anos setenta, passaram a fazer a seguinte indagação: há uma cultura pós-moderna, e mais, o que as novas formas culturais têm a ver com o conteúdo da pós-modernidade? Uma rápida constatação foi de que, independente de haver ou não pós-modernidade, a cultura havia assumido novas formas e maneiras inéditas de existência. A esse respeito Dunning ressalta:

"Com a descoberta de que a cultura estava em todos os lugares o estudo da cultura e a critica da cultura passam a ser uma parte cada vez mais na vida política e intelectual. Recentemente, isso passou a ser chamado de 'virada cultural' nas ciências humanas e sociais, e é geralmente associado à ascensão dos 'estudos culturais'”'. (DUNNING, 2006).

A observação de Dunning encontra ressonância nos trabalhos de Fredric Jameson. Em um dos seus últimos livros, não por acaso intitulado A virada cultural, sentencia que uma das conseqüências do pós-modernismo foi à dissolução da cultura de massa. $\mathrm{O}$ autor, ao sustentar tal implicação pós-moderna, se ampara nas transformações que levaram a especialização contumaz do consumo cultural e às alterações verificadas quanto à circulação e produção global dos bens culturais. Vai, assim, na mesma direção de Georg Yudice, que, em Conveniências da cultura, dedica boa parte de seu texto a emergência do mercado pós-massa, da mesma maneira que o supracitado Dunning dedica parte de seu texto ao capítulo intitulado $O$ fim da cultura de massa. Esse último, citando o próprio Jameson, ressalta que a maior mudança metodológica em termos dos estudos da cultura passou a ser a constatação de que a cultura era agora central à vida política e econômica. A partir de tal assertiva Jameson sustenta:

"Deveríamos perguntar aos sociólogos da manipulação se eles habitam o mesmo mundo que nós? (....) a cultura, longe de ser uma matéria ocasional da leitura de um bom livro mensal ou um passeio ao dive-in, segundo me parece, é o verdadeiro elemento da sociedade de consumo (....) tudo é medido pela cultura, até o ponto de que mesmo os níveis políticos e ideológicos tiveram inicialmente de ser desemaranhados de seu modo básico de representação que é cultural." (JAMESON, 2006).

Na percepção desses autores, a partir dos anos setenta, o que antes parecia cindido e separado, ou seja, encerrado na equação dos três níveis de organização da esfera cultural ("erudito", "popular" e "massivo") passam a fazer parte do mesmo amálgama. Assim, de George Yudice, nos Estados Unidos, 
passando por Zygmunt Bauman, na Europa, até Nestor Garcia Canclini, na América Latina, todos são solidários em sustentar que, por um lado, houve um aprofundamento da relação entre mercado, consumo e cultura e, que por outro, houve também uma grande segmentação e diferenciação desse consumo cultural. Essa trama de ralação esta ligada a uma rede maior de expansão e profissionalização das diversas atividades artísticas e culturais; pela intensificação e simultaneidade dos fluxos informacionais e comunicacionais; pelo estreitamento das cadeias de interdependências comerciais e econômicas, pela dissolução de antigas culturas nacionais e surgimento de novas identidades e formas de pertencimento; pela aproximação das diferenças em âmbito mundial; pela formação de circuitos globais de viagens que fortalecem o turismo cultural; pela consolidação de certos eixos mundiais de diversão e entretenimento, como festas transnacionais (carnaval brasileiro, por exemplo) e eventos esportivos.

Poderíamos pensar, assim, que esses autores confirmam a lenta agonia experimentada pelo conceito de indústria cultural, já que as mudanças acionadas nas ultimas décadas do século passado retiraram-lhe parte da sua vitalidade analítica. No entanto, a nova moralidade que sustenta a teia discursiva de justificativas em torno da relação cultura e capitalismo achava-se em plena tessitura nos anos oitenta, momento em que a maioria desses autores começaram a escrever sobre o tema. $\mathrm{O}$ deslocamento do olhar e as revisões internas ao conceito ocorreram muito antes. Em suas formulações sobre indústria cultural presente na primeira publicação (1967) de Cultura de massa no século XX, Edgar Morin destaca que a estruturação da indústria cultural, sua divisão do trabalho e seus mecanismos internos de funcionamento estão acentuados em um complexo equilíbrio entre produção e criação.

$\mathrm{O}$ autor concentra o tônus da analise no que segundo ele seria o grande desafio da indústria cultural, ou seja, a necessidade de conciliar auto-renovação dos conteúdos, da inovação e da busca permanente pelo novo com as inclinações de burocratização e padronização próprias aos demais modelos de organização industrial do trabalho. $\mathrm{O}$ aumento dessa última dimensão leva necessariamente a diminuição da primeira. Essa é, segundo o autor, uma contradição que a indústria cultural busca superar. A indústria cultural deve, pois, superar constantemente uma contradição fundamental entre suas estruturas burocratizadas-padronizadas e a originalidade (individualidade e novidade) do produto que ela deve fornecer. Seu próprio funcionamento se opera a partir desses dois pares antitéticos: burocraciainvenção versus padrão-individualidade. $\mathrm{O}$ autor sustenta ainda que esses pares antitéticos abrigam um conjunto complexo de aspectos (público, conteúdo, local, custo, etc.) que uma mudança em qualquer um deles afeta os demais. O delicado equilíbrio e definido como o ponto mesmo de vitalidade que alimenta a cultura de massa. A contradição entre invenção e padronização é a contradição dinâmica da cultura de massa. É o seu mecanismo de adaptação ao público e de adaptação do público a ela. É sua vitalidade última. (MORIN, 1967). 


\begin{abstract}
"A indústria do detergente produz sempre o mesmo pó, limitando-se a variar as embalagens de tempos em tempos. A indústria automobilística só pode individualizar as series anuais por renovações técnicas ou de formas, enquanto as unidades são idênticas umas as outras. No entanto, a indústria cultural precisa de unidades necessariamente individualizadas. Um filme pode ser concebido em função de algumas receitaspadrão (intriga amorosa, happy end.), mas deve ter sua personalidade, sua originalidade, sua unicidade. Do mesmo modo, um programa de radio, uma canção. Por outro lado, a informação, a grande imprensa, pescam cada dia o novo, o contingente, o acontecimento, isto e, o individual. Fazem o acontecimento passar nos seus moldes para restitui-los em sua unicidade." (MORRIN, 1969, p.78).
\end{abstract}

As observações de Morin são substancialmente distintas dos vaticínios críticos contidos nas formulações originais do conceito de indústria cultural. Elas abrem uma senda promissora para estudos empíricos acerca de aspectos que envolvem a divisão do trabalho cultural, as maneiras de racionalização do tempo de programação (rádio, televisão, cinema), os impactos semiológicos e estéticos na percepção, os mecanismos de formação e negociação do gosto, as diferenças entre técnicas, linguagens, setores e conteúdos, entre outros. O autor corrobora, assim, para a abertura de uma frente de pesquisa empírica rigorosa e sistemática que possa pensar a produção, a recepção, o consumo e as mediações. Por outro lado, o tenso equilíbrio destocado pelo autor, isto é, a necessidade de se manter o primado da inovação sem se deixar engolfar pelas rotinas de padronização, releva a grande lei de ferro da produção cultural contemporânea e, por conseguinte, do capitalismo tardio das sociedades pós-indústrias (BELL, 1973).

Em face da intensificação do processo de industrialização do simbólico e das transformações econômicas experimentadas a partir dos anos setenta, é sugestivo aventar a hipótese de que a principal mudança no âmbito da produção simbólicocultural contemporânea foi de ordem discursiva, envolvendo principalmente o núcleo semântico e teórico de categorias como indústria cultural, cultura e desenvolvimento. Nos próximos capítulos tais categorias serão tratadas como formulações nativas, tecidas, utilizadas e remanejadas de acordo com as conveniências e contingências que envolvem determinados grupos políticoculturais, organizações não-governamentais (ONGs), instituições públicas, organizações, empresas e governos inscritos nos processos de legitimação cultural. As mudanças instiladas em tais categorias vêm formando novas redes discursivas, que, por seu turno, estruturam novas práticas discursivas (FOUCAULT, 1986).

Latitude, Vol. 2, $\mathrm{n}^{\circ} 1, \mathrm{pp} .82-105,2008$. 


\section{Considerações finais}

Como se pode depreender, a escolha do conceito de indústria cultural cumpre, de certa forma, uma função heurística, pois permite compreender como determinadas categorias e conceitos próprios do universo circunscrito das ciências sociais, como classe, ideologia ,cultura, dominação, entre outros, penetram e formam as pautas e os repertórios lingüísticos e simbólicos de grupos sociais mais amplos, municiando-os nas lutas e tensões político-sociais. No caso do Brasil, as condições de possibilidade de ampliação do poder político e simbólico de tais categorias e conceitos, levadas a cabo mediante a estruturação de certos grupos e gerações político-culturais, se deram a partir da intensificação e consolidação do processo de modernização cultural.

Por outro lado, a compreensão especifica dos usos e dos efeitos práticos do conceito de indústria cultural na segunda metade do século XX faculta o entendimento, por vezes truncado e claudicante, das transformações conceituais e políticas ocorridas no núcleo de significado dessa categoria nas últimas duas décadas. $\mathrm{O}$ que se vê, mediante discussões acadêmicas, tratados e convenções internacionais, como as convenções publicadas pela UNESCO nesta década, assim as publicações que subsidiam as formulações e execuções das políticas culturais públicas e privadas, é a progressiva substituição da categoria de indústria cultural por outras formulações conceituais, como indústrias da criatividade e economia criativa. As razões especificas que presidem essas mudanças fogem a alçada deste trabalho, por hora é suficiente e possível assegurar que a direção dessa mudança e os novos valores e conteúdos que a impulsionam podem ser melhor compreendidos à luz dos usos práticos destacados aqui, assim como do trânsito simbólico e discursivo no qual se situam as categorias analíticas e as categorias nativas.

\section{Bibliografia}

ADORNO, Teodor e HORKEIMER, Max. Dialética do esclarecimento. Rio de Janeiro: Jorge Zahar Editor, 2000.

ADORNO, Teodor. Teoria estética. 2a Edição, Lisboa: Edições 70, 2008.

BAUMAN, Zygmun. Em busca da política. Rio de Janeiro: Jorge Zahar Editor, 2000. . Vida para o consumo. Rio de Janeiro: Jorge Zahar Editor, 2007.

BELL, Daniel. The coming post-industrial society. New York: Basic books, 1973.

BENJAMIN, Walter. Magia e técnica, arte e politica. São Paulo, Brasiliense, 2002.

BOLAÑO, César. Indústria cultural, informação e capitalismo. São Paulo, Polis, 2000.

BURKE, Peter. Cultura popular na idade média. São Paulo, Companhia das Letras, 2010.

BOURDIEU, Pierre. As regras da arte. Rio de Janeiro, Companhia das letras, 1998. 
A economia das trocas simbólicas. São Paulo, Perspectiva, 2005.

. Poder simbólico. Rio de Janeiro, Bertrand Brasil, 2002.

COHN, Gabriel, Comunicação e industria cultural. São Paulo: Editora A. Queiroz, São, 1978.

DENNING, Michael. A cultura na era dos três mundos. São Paulo: Editora Francis, 2004.

DUMAZIDIER, Jofre. Sociologia empírica do lazer. São Paulo: Perspectiva, 2004.

ELIAS, Norbert. Os alemães. Rio de Janeiro: Jorge Zahar Editor, 2001. . Mozart, a sociologia de um gênio. Rio de Janeiro: Jorge Zahar Editor, 2004. . O processo civilizador, Vol. II. Rio de Janeiro: Jorge Zahar Editor, 1997.

FOUCAULT, Michael. Arqueologia do saber. Rio de Janeiro: Forense, 1986.

GEERTZ, Clifford. A interpretação das culturas. São Paulo: LTC Editora, 2000.

GIDDENS, Anthony. Modernidade e identidade. Rio de Janeiro: Jorge Zahar Editor, 2002.

HUGHES, Howard, Artes, entretenimento e turismo. Rio de Janeiro, Roca, 2004.

JAMESON, Fredric. A virada cultural. Rio de Janeiro: Civilização Brasileira, 2006.

MANNHEIM, Karl. Sociologia da cultura. São Paulo, Perspectiva, 1974.

MANDEL, Ernest. O capitalismo tardio. São Paulo, Abril cultural, 1982.

MARCUSE, Herbert. Cultura e sociedade. São Paulo: Paz e Terra.

MICELI, Sérgio. A noite da madrinha. $2^{\circ}$ edição, São Paulo: Companhia das Letras, 2005.

MORIN, Edgard. Cultura de massa no século XX. São Paulo, Forense Universitária, 1967.

ORTIZ, Renato. A moderna tradição brasileira. São Paulo: Brasiliense, 2001.

. Modernidade e cultura. São Paulo: brasiliense, 1999.

RAMOS, José Mario Ortiz. Cinema, Estado e lutas culturais. São Paulo: Paz e Terra, 1983.

. Cinema, televisão e publicidade. $2^{\circ}$ edição, São Paulo: Annablume, 2004.

RUSKIN, John. Economia política da arte. São Paulo: Record, 2004.

SENNETT, Richard, A cultura do novo capitalismo. Rio de Janeiro: Record, 2006.

SCHUTZ, Alfred. Estudios sobre teoria social. Madri: Punto de Lectura, 1978.

SOUZA, Jessé. A atualidade de Max Weber. Brasília: UnB, 2000.

TINHORÃO, José Ramos. História social da música brasileira. São Paulo: Editora 34.

TOLILA, Paul. Economia e cultura. São Paulo: Iluminuras, 2007.

WEBER, MAX. Ensaios de sociologia. São Paulo: LTC Editora, 1982.

WIGGERSHAUS, Rolf. A escola de Frankfurt. Rio de Janeiro: Diffel, 2005.

WILLIAMS, Raymond, Cultura e sociedade. São Paulo: Paz e terra, 1989.

Latitude, Vol. 2, $\mathrm{n}^{\circ} 1, \mathrm{pp} .82-105,2008$. 
YÚDICE, George. Conveniências da cultura. Belo Horizonte: Editora Humanitas, 2005.

Latitude, Vol.2, $n^{\circ} 1, \mathrm{pp} .82-105,2008$. 